DOI: http://dx.doi.org/10.18569/tempus.v13i3.2612

\title{
Saúde bucal de refugiados no século XXI: revisão integrativa
}

\section{Refugee oral health in the 21 st century: integrative review}

\section{La salud oral de los refugiados en el siglo XXI: revisión integrativa}

Paolla Zellya Borges

Beatriz Unfer ${ }^{2}$

Daniel Demétrio Faustino-Silva ${ }^{3}$

\begin{abstract}
RESUMO: Este trabalho tem por objetivo conhecer e analisar a situação de saúde bucal de refugiados, a fim de planejar ações e serviços e ampliar políticas públicas para esta população no Brasil e no mundo. O método de pesquisa utilizou a Revisão Integrativa para a síntese do conhecimento sobre o tema. Foi utilizada a base de dados Scopus e selecionadas 21 publicações na língua inglesa, sendo que nenhuma trata do tema no Brasil. Os resultados indicaram que os principais problemas bucais são cárie dentária e doença periodontal. São levantadas questões relativas aos costumes, crenças e conhecimentos prévios que influenciam na saúde bucal destas populações e o "efeito imigrante saudável", quando o fenômeno da aculturação pode influenciar negativamente na saúde do reassentado. Mecanismos para o adequado atendimento de populações refugiadas podem ser encontrados nas Políticas Públicas de Saúde brasileiras, sendo necessária sua ampliação, adequando-as à situação atual de migração. Os profissionais de saúde devem ser preparados para lidar com a cultura e as experiências anteriores dessa população com relação aos cuidados bucais, criando vínculos desde o momento de sua chegada ao país.
\end{abstract}

Palavras-chave: Refugiados. Saúde Bucal. Cárie Dentária. Doença Periodontal.

RESUMEN: Este documento tiene como objetivo conocer y analizar la situación de salud oral de los refugiados, a fin de planificar acciones y servicios y ampliar las políticas públicas para esta población en Brasil y en todo el mundo. El método de investigación utilizó la Revisión Integrativa

\footnotetext{
1 Grupo Hospitalar Conceição-GHC

2 Universidade Federal de Santa Maria-UFSM

3 Grupo Hospitalar Conceição-GHC- Serviço de Saúde Comunitária - Programa de Pós-graduação em Avaliação e Produção de Tecnologias para o SUS
}

ISSN 1982-8829 Tempus, actas de saúde colet, Brasília, 13(3), 123-137, set, 2019. Epub Jul/2020 
para la síntesis del conocimiento sobre el tema. Utilizamos la base de datos Scopus y seleccionamos 21 publicaciones en inglés, ninguna de las cuales trata el tema en Brasil. Los resultados indicaron que los principales problemas orales son la caries dental y la enfermedad periodontal. Se plantean preguntas sobre las costumbres, creencias y conocimientos previos que influyen en la salud oral de estas poblaciones y el "efecto inmigrante saludable", cuando el fenómeno de la aculturación puede influir negativamente en la salud de la persona reasentada. Los mecanismos para la atención adecuada de las poblaciones de refugiados se pueden encontrar en las Políticas de Salud Pública de Brasil, y su expansión es necesaria, adaptándolas a la situación migratoria actual. Los profesionales de la salud deben estar preparados para lidiar con la cultura y las experiencias previas de esta población con respecto al cuidado bucal, creando vínculos desde el momento de su llegada al país. Palabras clave: Refugiados. Salud Bucal. Caries Dental. Enfermedades Periodontales.

\begin{abstract}
This study aims to know and analyze the oral health situation of refugees, in order to plan actions and services and expand public policies for this population in Brazil and worldwide. The research method used the Integrative Review for the synthesis of knowledge on the subject. Scopus database was used and 21 publications selected in English, none of which deals with the topic in Brazil. The results indicated that the main oral problems are dental caries and periodontal disease. Questions are raised regarding the customs, beliefs and previous knowledge that influence the oral health of these populations and the "healthy immigrant effect", when the phenomenon of acculturation can negatively influence the health of the resettled person. Mechanisms for the proper care of refugee populations can be found in the Brazilian Public Health Policies, being necessary to expand and adapting them to the current migration situation. Health professionals must be prepared to deal with the culture and previous experiences of this population regarding oral care, creating bonds from the moment of their arrival in the country.
\end{abstract}

Key words: Refugees. Oral Health. Dental Caries. Periodontal Diseases.

\title{
INTRODUÇÃO
}

Imigrantes são aqueles que, de livre vontade, preparam-se com antecedência para a busca de um novo projeto de vida em um país estrangeiro, com a perspectiva de uma melhor qualidade de vida e possibilidade de prosperar. Refugiados são uma população com maior vulnerabilidade, porque são forçados a saírem de seus países, por motivos diversos, como guerras, perseguições e dificuldades econômicas. ${ }^{1}$

Nas últimas décadas, o fluxo migratório tem sido intenso, dentro e fora dos limites do Brasil. Um país de "emigração" pode ser considerado expulsivo, com problemas de ordem social, política e econômica; já um país de "imigração" é aquele que possui atrativos de qualidade de vida para a população, como saúde, educação e moradia, além de buscar ser uma nação acolhedora ${ }^{2}$

O termo "refugiado" foi usado para descrever os calvinistas que fugiam da repressão política na Holanda para a França, no ano de 1500. Mas os refugiados não foram apenas definidos como 
vítimas de perseguição; eles também eram vistos como indivíduos com interesses políticos, religiosos, afiliações econômicas ou outras que despertaram a solidariedade entre aqueles que apoiavam interesses semelhantes em outros países e um correspondente senso de responsabilidade em relação a eles. ${ }^{3}$

O sujeito imigrante sempre foi visto de forma "exótica". Sempre um sujeito à margem, não-cidadão, que para ser aceito precisa ter seu status de "imigrante" fixado, imutável, sempre provisório. Ainda, como mão de obra barata, que deve trazer benefícios aos cidadãos naturais daquele país, daquele estado. Tendo sempre direitos parciais - afinal, para serem plenos, somente quando nacionais daquele território - um deles sempre tão negligenciado - a saúde, principalmente a saúde mental. ${ }^{4}$

A Convenção das Nações Unidas relativa ao Estatuto dos Refugiados de 1951 cita que estes sujeitos, temendo perseguição por motivos de etnia, religião, nacionalidade, grupo social ou político, encontra-se fora do país de sua nacionalidade e não pode ou não quer voltar a ele por esse referido temor. ${ }^{5}$

Por meio de acordos de cooperação técnica e científica entre Brasil e Haiti, em 2004 começou um fluxo migratório intenso de haitianos para o Brasil, ${ }^{1}$ quando o Brasil enviou mais tropas a serviço da Missão de Paz da Organização Mundial das Nações Unidas (ONU) - a Minustah. ${ }^{6}$ A Missão atuou por 13 anos, auxiliando na estabilização do país após um terremoto em 2010 e um furacão em 2016, ambos de consequências catastróficas, finalizando seus trabalhos em 2017. Atualmente, há uma nova missão de manutenção da paz no território. ${ }^{7}$

Os pedidos de refúgio ao Brasil aumentam com o passar dos anos. Desconsiderando a chegada de venezuelanos e haitianos, foram 13.639 pedidos em 2017, 6.287 em 2016, 13.383 em 2015 e 11.405 em 2014. Em 2017, foram registradas mais de 80 mil solicitações de refúgio. Segundo a Polícia Federal, o Rio Grande do Sul possuía apenas $2 \%$ dos pedidos de refúgio do país, totalizando 767 solicitações. $^{8}$

Conforme o artigo $4^{\circ}$ da Lei da Migração brasileira, de 2017, ao migrante são garantidos vários direitos tais qual aos nacionais, entre eles o direito ao acesso a serviços públicos de saúde. ${ }^{9}$ Esta situação já estava prevista na Resolução Normativa n ${ }^{\circ} 14$ de 27 de dezembro de 2011, na qual o artigo 22 cita que os refugiados terão acesso ao sistema público de saúde em condição de igualdade conforme se pode constatar no formulário de solicitação de refúgio que deve preencher. ${ }^{10}$

No Brasil o sistema de saúde público é o Sistema Único de Saúde (SUS), consolidado pela Lei n. 8.080 de 1990. Conforme o artigo $4^{\circ}$, é constituído pelo "conjunto de ações e serviços de saúde, prestados por órgãos e instituições públicas federais, estaduais e municipais, da Administração direta e indireta e das fundações mantidas pelo Poder Público. ${ }^{11} \quad$ O SUS considera que nenhum tipo de atendimento pode ser negado a qualquer pessoa, principalmente quando se fala em atenção 
básica, que é a porta de entrada do sistema, inclusive para a população refugiada. Para que o acesso e atendimento dessa população seja de forma integral, universal e equânime, devem ser adotadas estratégias e políticas de saúde. ${ }^{12}$

Considerando o cenário internacional com relação à migração de populações, notadamente de refugiados, este estudo teve como objetivo conhecer e analisar a situação de saúde bucal de refugiados, a fim de subsidiar o planejamento de ações e serviços, bem como a ampliação das políticas públicas de saúde no Brasil e em outros países do mundo.

\section{MÉTODOS}

O método de pesquisa utilizou a Revisão Integrativa para a síntese do conhecimento, por meio da revisão da literatura relevante sobre o tema.

Foi realizada uma busca na base de dados Scopus, considerada a base de dados com maior oferta de periódicos e número de artigos que citam o tópico pesquisado. ${ }^{13}$

Foram utilizadas combinações dos descritores "refugiados", "saúde bucal", "cárie dentária" e “doença periodontal” nos idiomas português, inglês e espanhol.

Os critérios de inclusão foram: artigos publicados entre janeiro de 2004 e julho de 2019, disponíveis na íntegra e nos idiomas português, espanhol e inglês, cujas populações de estudo fossem da América (Haiti; Venezuela), África (Senegal; Angola; Nigéria; Congo; Gana), Ásia (Síria; Bangladesh; Líbano), pois representam o maior contingente de solicitações de refúgio no Brasil, segundo dados fornecidos pela Secretaria Nacional de Justiça. ${ }^{4}$ A especificação do ano de 2004 deve-se ao fato de que neste ano teve início a migração de haitianos para o Brasil.

Os dados extraídos dos artigos foram organizados em quadros e analisados descritivamente de forma a reunir as informações que sintetizassem o conhecimento e auxiliassem na compreensão sobre o fenômeno estudado.

\section{RESULTADOS}

A busca recuperou 1.082 textos. Foram selecionados 73 artigos por meio da leitura de títulos, resumos, referências. Após a leitura integral foram escolhidos 21 artigos que preencheram completamente os critérios de inclusão para a amostra final. O Quadro 1 sintetiza os 21 estudos quanto ao objetivo, a população envolvida, os principais resultados e conclusões.

As publicações são na língua inglesa e nenhuma trata do tema no Brasil. A quase totalidade dos textos (90\%) abordam a saúde bucal na população de refugiados $14,15,17,18,19,20,21,22,23,24,26,28,29,30,31,32,33,34$ enquanto três ${ }^{16,25,27}$ abordam sobre imigrantes e refugiados. 
Dos textos selecionados, 11 englobam todas as idades ${ }^{14,20,21,23,24,25,26,27,28,29,30}$, sete têm como assunto principal a saúde bucal de crianças refugiadas ${ }^{16,17,19,22,31,33,34}$, um é exclusivo sobre adolescentes ${ }^{15}$, e um exclusivo sobre adultos ${ }^{19}$.

Os principais problemas bucais que acometem os refugiado são cárie dentária, doenças periodontais e dor dentária. A maioria dos estudos aborda as condições bucais e a atenção odontológica $14,15,17,18,19,21,22,23,24,25,26,27,28,29,30,31,32,33,34$ e dois analisam as percepções de saúde bucal nesta população ${ }^{16,22}$. Dois estudos salientam que existe dificuldade na procura por serviços odontológicos, devido a diversas barreiras ${ }^{15,29}$. Outros estudos salientam a necessidade de organizar adequadamente os serviços de saúde nos países que recebem refugiados, facilitando o acesso e ampliando o atendimento das necessidades de saúde, incluindo a saúde bucal ${ }^{14,17,21,22,23,24,26,28,30,31,32,33,34}$.

Três estudos tratam da vulnerabilidade dos refugiados em relação a imigrantes e nativos ${ }^{24,25,27,34}$ enquanto outros abordam o processo de aculturação que ocorre quando esta população encontra refúgio nos países que os recebem ${ }^{16,22,23,32}$. Barreiras linguísticas, crenças, hábitos e atitudes são levantados em alguns textos, salientando as dificuldades no manejo da saúde nestas populações ${ }^{16,19,22,28,32,33,34}$.

Quadro 1. Síntese qualitativa dos dados obtidos nos estudos segundo população envolvida, objetivo, principais resultados e conclusão, 2019.

POPULAÇÃO DE ESTUDO e OBJETIVO

PRINCIPAIS RESULTADOS E CONCLUSÃO

1. T M Roucka. Access to dental care in two long-term refugee camps in western Tanzania; programme development and assessment. International Dental Journal, 2011; 61: 109-115

- Pessoas de todas as idades e O principal motivo para a procura pelo atendimento odontológico foi a dor para $99 \%$ dos trabalhadores de saúde. $\quad$ pacientes $(\mathrm{n}=1.944)$. Edema foi o segundo motivo mais comum com $\mathrm{n}=53$ pacientes

- Origem: Borundi, Congo, ou 2,7\%, seguido pela doença periodontal em $\mathrm{n}=10$ pacientes, $0,5 \%$. A avaliação inicial Tanzânia. $\quad$ encontrou que a taxa de cárie dentária é mais alta no grupo adulto (70\%), seguido por

- Analisar dados demográficos e de crianças menores de 12 anos (64\%) e adolescentes (31\%). A maioria dos pacientes, sustentabilidade de um Programa 95,5\%, recebeu extrações dentárias como tratamento $(\mathrm{n}=1.876)$.

de Treinamento de trabalhadores $\mathrm{O}$ treinamento dos trabalhadores, embora de natureza rudimentar, forneceu atendimento de saúde em Atendimento odontológico de emergência e educação em promoção da saúde bucal para os residentes Odontológico de Emergência dos campos de refugiados e povos nativos, de forma segura, onde nunca existiram e Promoção da Saúde, em antes. Programas como este podem ser uma forma viável de abordar as necessidades de dois campos de refugiados na cuidados de saúde bucal de refugiados em outros locais onde existam acampamentos de Tanzânia Ocidental.

longa permanência.

2. G Sarri; P Evans; S Stansfeld; W Marcenes. A school-based epidemiological study of dental neglect among adolescents in a deprived area of the UK. British Dental Journal, 2012; 213: E17

- Adolescentes.

- Relatar a prevalência de dois Os adolescentes refugiados tinham probabilidade duas vezes maior de experimentar tipos de negligências dentárias: negligência de prevenção dentária (58,5\%) em comparação com não refugiados (39,5\%). de prevenção e de tratamento Uma proporção maior de adolescentes refugiados $(58,3 \%)$ apresentou negligência de dentário, definidas por tratamento dentário em comparação com adolescentes não refugiados $(44,9 \%)$.

indicadores clínicos de saúde Intervenções públicas em saúde bucal referentes às negligências dentárias podem ser bucal precária e por uma medida mais relevantes para adolescentes carentes cujas necessidades odontológicas estão sob do impacto relacionado à saúde risco maior de negligência do que para adolescentes da população em geral. Assim como bucal dos adolescentes que as negligências dentárias podem coincidir com outros tipos de negligência infantil, os frequentam escolas secundárias recursos poderiam ser alocados de forma mais eficiente. em uma área urbana carente.

3. E Riggs; L Gibbs; N Kilpatrick; M Gussy; C van Gemert; S Ali; E Waters. Breaking down the barriers: a qualitative study to understand child oral health in refugee and migrant communities in Australia. Ethnicity \& Health, 2015; 20; 3:241-257

ISSN 1982-8829 Tempus, actas de saúde colet, Brasília, 13(3), 123-137, set, 2019. Epub Jul/2020 


\begin{tabular}{|c|c|}
\hline $\begin{array}{c}\text { POPULAÇÃO DE ESTUDO e } \\
\text { OBJETIVO }\end{array}$ & PRINCIPAIS RESULTADOS E CONCLUSÃO \\
\hline $\begin{array}{l}\text { - Mães, avós e cuidadoras de } \\
\text { crianças de 0-12 anos. } \\
\text { - Origem: Paquistão, Iraque e } \\
\text { Líbano. } \\
\text { Explorar as influências } \\
\text { socioculturais sobrer o o } \\
\text { conhecimento, crenças e práticas } \\
\text { de saúde bucal infantil em três } \\
\text { comunidades migrantes em } \\
\text { Melbourne, Austrália. }\end{array}$ & $\begin{array}{l}\text { Muitas relataram que a cárie dentária infantil não era um problema em seus países de } \\
\text { origem e não conseguiam entender por que seus filhos agora a experimentavam. O } \\
\text { flúor era um conceito novo para quase todas as participantes. Todas as participantes } \\
\text { falaram sobre a falta de atenção dada à higiene bucal em seus países de origem, porque } \\
\text { as pessoas tinham uma boa saúde bucal e tinham poucos motivos para se preocupar. } \\
\text { Antes de migrar para a Austrália, muitas nunca haviam usado uma escova de dentes ou } \\
\text { pasta de dentes. Houve muita confusão sobre quando introduzir a escovação e pasta de } \\
\text { dente para crianças. Isto porque a escovação em crianças pequenas era, em grande parte, } \\
\text { uma prática nova para os pais. E os conselhos que receberam dos profissionais de saúde } \\
\text { eram incompletos ou conflitavam com suas próprias crenças. As participantes tiveram } \\
\text { uma boa compreensão das causas dietéticas da má saúde bucal em crianças. No entanto, } \\
\text { elas enfrentam dificuldades para controlar a dieta de seus filhos. Estão confusas sobre } \\
\text { as outras causas de cárie dentária, bem como quando começar a limpeza dos dentes das } \\
\text { crianças. As mães sabiam que havia informações disponíveis para as quais não estavam } \\
\text { sendo expostas, e expressaram o desejo de acessar essas informaçóes. Muitas vezes as } \\
\text { pessoas com histórico de refugiados não são alfabetizadas em sua própria língua, de modo } \\
\text { que a informação escrita traduzida nem sempre é útil. O dentista e outros profissionais } \\
\text { de saúde precisam fornecer informações consistentes e relevantes que sejam atentas ao } \\
\text { contexto cultural e migrante. } \\
\text { A experiência da migração junto com outros fatores, incluindo proficiência em inglês, } \\
\text { alfabetização em saúde, aculturação, crenças de saúde, educação anterior e status } \\
\text { socioeconômico, impacta na capacidade de um indivíduo de acessar informações e } \\
\text { serviços de saúde e provavelmente perpetuar condições de saúde ruins. }\end{array}$ \\
\hline
\end{tabular}

4. P Nicol; R Anthonappa; N King; L Slack-Smith; G Cirillo; S Cherian. Caries burden and efficacy of a referra pathway in a cohort of preschool refugee children. Australian Dental Journal, 2015; 60: 73-79

- Crianças menores de seis anos.

- Origem: Birmânia, Sri Lanka, Irã Afeganistão, países da África.

- Determinar a experiência de cárie precoce da infância e os fatores associados a presença da doença em crianças pré-escolares refugiadas, e a eficácia da triagem odontológica comunitária implantada recentemente.
Quase dois terços $(65 / 105,62 \%)$ tinham um escore ceo-d $>0$. Seis crianças $(5,7 \%)$ tinham inflamação gengival com um índice de inflamação $>0$. Havia apenas três crianças com dentes permanentes, e quatro dos nove dentes permanentes exibiram cáries. Houve correlação significativa entre idade e ceo-d. Crianças com ceo-d $>0$ foram significativamente mais velhas do que crianças com ceo-d $=0$. Não houve diferença significativa no ceo-d entre gênero, países de origem ou idioma.

Crianças pré-escolares refugiadas reassentadas têm doença bucal debilitante severa num contexto de múltiplas outras comorbidades médicas e questões psicossociais. Os serviços odontológicos disponíveis atualmente não conseguem ser eficazes. A tendência de aumento da cárie com a idade resultará em aumento da morbidade e dos custos econômicos. Há a necessidade de desenvolver um modelo de cuidado culturalmente apropriado, focado na criança e na família.

5. N Davidson; S Skull; G Chaney; A Frydenberg; D Isaacs; P Kelly; B Lampropoulos; S Raman; D Silove; J Buttery; M Smith Z Steel; D Burgner. Comprehensive health assessment for newly arrived refugee children in Australia. J. Paediatr. Child Health, 2004; 40: 562-568

- Crianças.

- Descrever os itens de avaliação da saúde de crianças refugiadas.
Doenças bucais são altamente prevalentes em imigrantes e refugiados. Os problemas bucais incluem cárie dentária, doença gengival, má oclusão e trauma dento facial. A saúde bucal é afetada pela sub e má nutrição, além do custo do tratamento, medo de autoridade, isolamento cultural, falta de comunicação e habilidade de linguagens, e crenças sobre tratamento odontológico. Os problemas dentários podem ser, também, consequência de tortura ou espancamento, e procurar atendimento odontológico em si pode ser uma experiência traumática.

As crianças refugiadas têm necessidades de saúde específicas que exigem uma atenção cuidadosa e com as quais os profissionais de saúde dos países desenvolvidos podem não estar familiarizados.

6. PL Geltman; JH Adams; J Cochran; G Doros; D Rybin; M Henshaw; LL Barnes; M Paasche-Orlow. The Impact of Functiona Health Literacy and Acculturation on the Oral Health Status of Somali Refugees Living in Massachusetts. Am J Public Health, 2013;103: 1516-1523 


\begin{tabular}{|c|c|}
\hline $\begin{array}{c}\text { POPULAÇÃO DE ESTUDO e } \\
\text { OBJETIVO }\end{array}$ & PRINCIPAIS RESULTADOS E CONCLUSÃO \\
\hline $\begin{array}{l}\text { - Adultos. } \\
\text { - } \text { Origem: Somália } \\
\text { em saúde e da aculturação no } \\
\text { estado de saúde dos refugiados } \\
\text { somalis em Massachusetts. }\end{array}$ & $\begin{array}{l}\text { Os participantes tinham, em média, } 1,4 \text { dentes cariados, } 2,8 \text { dentes ausentes e } 1,3 \text { com } \\
\text { restaurações. Entre os que estavam nos Estados Unidos de } 0 \text { a } 4 \text { anos, o escore menor de } \\
\text { alfabetização em saúde foi correlacionado com menor CPOD. Entre os participantes que } \\
\text { estavam no país de } 5 \text { a } 10 \text { anos, os escores de alfabetização mais baixos se correlacionaram } \\
\text { com maior CPOD. A alfabetização não foi significativamente associada com dentes } \\
\text { cariados. Escores mais baixos de letramento correlacionaram-se marginalmente com } \\
\text { menor risco de doença periodontal. } \\
\text { Os resultados indicaram que o agravamento da saúde bucal dos refugiados somalis ao } \\
\text { longo do tempo pode estar relacionado ao menor acesso a cuidados preventivos e à } \\
\text { menor utilização de práticas de higiene bucal. }\end{array}$ \\
\hline
\end{tabular}

7. A Quach; IL Laemmle-Ruff; T Polizzi; GA Paxton. Gaps in smiles and services: a cross-sectional study of dental caries in refugee-background children. BMC Oral Health, 2015; 15:10

- Crianças de 0-18 anos.

- Origem: África, Ásia, Oriente Médio e ilhas do Pacífico.

- Levantar dados sobre problemas de saúde bucal autorrelatados, achados de avaliação odontológica e uso de serviços odontológicos.

As preocupações autorrelatadas mais frequentes foram ortodontia / estética, dor e cárie. A experiência de cárie do grupo de refugiados com dentição mista foi de $66,9 \%$; quase todas as crianças com dentição mista nascidas no exterior. de países não africanos, tiveram experiência de cárie $(94,4 \%)$ (Ásia, Oriente Médio e região do Pacífico). A prevalência de cárie em crianças, predominantemente africanas, foi semelhante à de crianças australianas. Dados limitados sugerem uma maior prevalência de cárie em crianças refugiadas de países de origem não africana.

Apesar de a cárie ser comum, a preocupação dos pais com a saúde bucal é incomum, e a avaliação direta da saúde bucal é importante em crianças refugiadas.

8. V Johnston; L Smith; H Roydhouse. The health of newly arrived refugees to the Top End of Australia: results of a clinical audit at the Darwin Refugee Health Service. Australian Journal of Primary Health, 2012; 18: 242-247

- Crianças, adolescentes e adultos.

- Origem: países da Ásia e África.

- Relatar as condições de saúde de refugiados recém-chegados registradas em um serviço de saúde.

As condições de saúde documentadas mais comuns foram deficiência ou insuficiência de vitamina D (66\%), seguida por esquistossomose (24\%) e doença dentária (dor dentária e doença gengival) $(23 \%)$.

Os resultados destacam a necessidade contínua de advocacia para abordar as restrições de serviços, como o acesso odontológico público limitado para essa população.

9. P Nicol; A Al-Hanbali; N King; L Slack-Smith; S Cherian. Informing a culturally appropriate approach to oral health and dental care for pre-school refugee children: a community participatory study. BMC Oral Health, 2014; 14:69

- Pais de crianças com menos de 5 anos.

- Origem: Burma, Iraque, Kuwait Sudão, Afeganistão, Borundi, Ruanda, Nigéria, República Democrática do Congo.

- Explorar as percepções de comunidades de refugiados relativas às suas experiências com serviços de saúde bucal.

A maioria dos participantes não se preocupavam com os dentes decíduos das crianças, pois iriam cair de qualquer maneira. Lidar com a cárie precoce era feito sem visita ao um consultório odontológico. As formas tradicionais de cuidar dos dentes incluíam esfregar com carvão (Birmânia), mascar nozes de betel e pedras (Etiópia), miswak (varas) (Afeganistão), sal e pele verde de frutos de nozes ou nozes (Afeganistão). Os métodos tradicionais de alívio da dor de dente incluíam esfregar as gengivas com óleo de cravo (Birmânia) ou polpa quente (Sudão). Esses métodos foram passados pelos avós. Os participantes não tinham conhecimento do flúor e do seu papel na promoção de dentes saudáveis, e alguns expressaram o receio de que fosse cancerígeno.

As dificuldades de reassentamento foram identificadas como uma grande barreira para o entendimento e uso de serviços odontológicos. Questões sociais, especialmente habitação, comida, transporte e saúde mental tendem a ser as principais prioridades das famílias.

10. AY Shah; PS Suchdev; T Mitchell; S Shetty; C Warner; A Oladele; S Reines. Nutritional status of refugee children entering DeKalb County, Georgia. J Immigrant Minority Health, 2014; 16: 959-967

- Crianças de 0-18 anos.

- Origem: países da Ásia, África, Oriente Médio, Cuba e Colômbia.

- Determinar a prevalência de anemia, desnutrição e condições médicas relacionadas entre as crianças refugiadas.
Exames odontológicos em 366 refugiados mostraram que pouco menos da metade $(44,8 \%)$ tinha cáries dentárias. Apenas um em cada dez refugiados africanos teve cárie dentária ao exame (10,6\%), comparado a quase metade dos refugiados butaneses $(50,0 \%)$ e birmaneses (48,0\%). Aproximadamente metade do subgrupo da Tailândia (50,0\%) e do subgrupo da Malásia (45,3\%) tinham cárie dentária.

Como os EUA continuam a receber a maioria dos refugiados reassentados em um terceiro país, os médicos que cuidam de refugiados pediátricos devem ter um papel ativo na compreensão dos problemas comuns de saúde enfrentados por essas crianças.

11. M Reza; M Amin; A Sgro; A Abdelaziz; D Ito; P Main; A Azarpazhooh. Oral health status of immigrant and refugee children in North America: A scoping review. J Can Dent Assoc., 2016; 82: g3 


\begin{tabular}{|c|c|}
\hline $\begin{array}{l}\text { POPULAÇÃO DE ESTUDO e } \\
\text { OBJETIVO }\end{array}$ & PRINCIPAIS RESULTADOS E CONCLUSÃO \\
\hline $\begin{array}{l}\text { - } 32 \text { estudos da América do Norte. } \\
\text { - Avaliar o estado de saúde bucal } \\
\text { dos filhos de refugiados e } \\
\text { imigrantes; as barreiras à atenção } \\
\text { adequada à saúde bucal e ao } \\
\text { uso de serviços odontológicos; } \\
\text { e intervenções clínicas e } \\
\text { comportamentais para essa } \\
\text { população na América do Norte. }\end{array}$ & $\begin{array}{l}\text { Em geral, os filhos de recém-chegados apresentam pior saúde bucal em comparação } \\
\text { com seus pares não recém-chegados. Essa população enfrenta barreiras linguísticas, } \\
\text { culturais e financeiras que, consequentemente, limitam seu acesso e uso de serviços } \\
\text { odontológicos. Programas de intervenção, como cursos educacionais e aconselhamento, } \\
\text { visando pais recém-chegados ou seus filhos são úteis para melhorar o estado de saúde } \\
\text { bucal dessa população. Filhos de recém-chegados estão sofrendo de má saúde bucal e } \\
\text { enfrentam várias barreiras ao uso de serviços odontológicos. } \\
\text { A disparidade na cárie dentária entre crianças de recém-chegados e suas contrapartes } \\
\text { pode ser reduzida melhorando a alfabetização de seus pais na (s) língua (s) oficial (is) e } \\
\text { educando os pais sobre boas práticas de saúde bucal. Uma política apropriada de saúde } \\
\text { bucal continua a ser crucial para as populações marginalizadas em geral e as recém- } \\
\text { chegadas em particular. }\end{array}$ \\
\hline
\end{tabular}

12. J Hoover; H Vatanparast; G Uswak. Risk determinants of dental caries and oral hygiene status in 3-15-year-old recent immigrant and refugee children in Saskatchewan, Canada: A pilot study. J Immigrant Minority Health. Published online: 27 June 2016

- Crianças de imigrantes refugiados recentes de 3 a 15 anos e 86 adultos.

- Identificar os determinantes de risco da cárie e registrar o estado de higiene bucal em crianças recém-imigrantes e refugiadas.

Crianças refugiadas tiveram estaticamente mais dentes cariados, ausentes e restaurados (ceo/CPOD médio de 5,8) do que crianças imigrantes (ceo/CPOD médio de 3,52), consideravelmente mais alta que em crianças nascidas no Canadá $(0,49)$. Os imigrantes adultos apresentaram proficiência significativamente maior em língua inglesa e conhecimento sobre componentes preventivos como flúor e fio dental comparado aos adultos refugiados.

Em geral, os imigrantes e refugiados têm outras prioridades e preocupações para lidar, como o estresse associado à adaptação a uma nova cultura, o aprendizado do inglês como segunda língua, problemas com transporte, finanças e encontrar escolas para as crianças, antes de poderem considerar as necessidades de saúde bucal de seus filhos. Mesmo que eles desejem procurar atendimento odontológico, a maioria acha o custo do tratamento regular em um consultório odontológico privado, proibitivo, especialmente porque a maioria dos recém-chegados não tem seguro odontológico ou os meios financeiros para cobrir o custo.

13. R C Mutch; S Cherian; K Nemba; J S Geddes; D M Rutherford; G M Chaney; D P Burgner. Tertiary paediatric refugee health clinic in Western Australia: Analysis of the first 1026 children. Journal of Paediatrics and Child Health, 2012; 48: 582-587

- 1026 crianças ( 0 a 17 anos) de 475 A cárie dentária era comum e frequentemente severa; no entanto, os sintomas raramente famílias de 30 etnias diferentes.

- Origem: Sudão e Burma.

- Descrever a epidemiologia das condições comuns em refugiados pediátricos reassentados atendidos em uma clínica multidisciplinar de saúde para refugiados. foram relatados. A falta de relato de dor evidencia a necessidade de um exame clínico completo em crianças refugiadas, pois o histórico de sintomas não indicou patologia de maneira confiável. Uma maior prevalência de cárie dentária relatada entre crianças refugiadas reassentadas nos EUA pode ter resultado da pesquisa concluída com o envolvimento de um especialista em odontologia.

O acesso a serviços odontológicos acessíveis para crianças refugiadas pré-escolares é difícil; envolver especialistas em odontologia no momento da primeira revisão otimizaria o reconhecimento da patologia e pode facilitar o envolvimento terapêutico.

14. E Ghiabi; D C Matthews; M S Brillant. The oral health status of recent immigrants and refugees in Nova Scotia, Canada. Immigrant Minority Health, 2014; 16:95-101

- 45 imigrantes de 12 países e 41 Mais da metade (53\%) dos imigrantes e $85 \%$ dos refugiados tiveram caries não tratadas. refugiados Butaneses de 18 a 67 A maioria (89\% dos imigrantes; 98\% dos refugiados) tinha gengivite moderada a grave e anos.

- Origem: Irã, China, Coréia do a grave. Apesar disso, $64 \%$ dos imigrantes e $49 \%$ dos refugiados classificaram sua saúde Sul.

- Relatar pesquisa de saúde restaurações ou tratamento periodontal. bucal em grupo de imigrantes A doença bucal na amostra do estudo foi maior do que a média canadense e houve uma e refugiados recentes em Nova discrepância marcante entre a necessidade de atendimento odontológico auto relatada e Scotia, Canadá. clinicamente determinada.

15. K Goetz; W Winkelmann; J Steinhäuser. Assessment of oral health and cost of care for a group of refugees in Germany: a cross-sectional study. BMC Oral Health, 2018; $18: 69$

Tempus, actas de saúde colet, Brasília, 13(3), 123-137, set, 2019. Epub Jul/2020 ISSN 1982-8829 


\begin{tabular}{|c|c|}
\hline $\begin{array}{c}\text { POPULAÇÃO DE ESTUDO e } \\
\text { OBJETIVO }\end{array}$ & PRINCIPAIS RESULTADOS E CONCLUSÃO \\
\hline $\begin{array}{l}\text { - Jovens e adultos. } \\
\text { Origem: Afeganistão, Iraque e } \\
\text { Síria. } \\
\text { Avaliar a saúde bucal dos } \\
\text { refugiados em uma região da } \\
\text { Alemanha estimar os custos dos } \\
\text { cuidados bucais. }\end{array}$ & $\begin{array}{l}\text { Mais de } 84 \% \text { (n=94) não visitaram um dentista regularmente durante a infância. Quase } \\
50 \% \text { dos participantes praticavam a higiene dental duas vezes ao dia. A presença de } \\
\text { dor de dente afetou } 49 \% \text { dos participantes. O índice CPO-D teve uma média de } 6,89 \text {. } \\
\text { A dentição saudável esteve presente em } 13,7 \% \text { dos participantes. Um índice CPO-D } \\
\text { moderadamente alto }(>9,0) \text { foi observado em } 25,5 \% \text { dos refugiados. Para } 92 \% \text { alguma } \\
\text { forma de tratamento foi indicada. } \\
\text { Deve-se considerar se uma triagem de saúde bucal poderia fazer parte de um exame } \\
\text { médico inicial. Ferramentas padronizadas para avaliações de saúde bucal estão } \\
\text { disponíveis na OMS e podem ser usadas por estudantes de odontologia em estágio } \\
\text { avançado. Essas avaliações ajudariam na prevenção de doenças orais. }\end{array}$ \\
\hline
\end{tabular}

16. M Solyman; A-M S-Westhausen. Oral health status among newly arrived refugees in Germany: a cross-sectional study. BMC Oral Health, 2018; 18:132

- Adultos de 18-60 anos.

- Origem: Síria e do Iraque.

- Determinar o estado da saúde bucal de refugiados recém chegados na Alemanha e explorar seus conhecimentos, atitudes práticas sobre higiene bucal.

$87,5 \%$ dos participantes tinham cárie não tratada. A média do CPOD foi de $6,38 \mathrm{com}$ cariados, perdidos e obturados apresentando escores médios de 4,00, 1,46 e 0,92 respectivamente. $79 \%$ tinham placa bacteriana em todos os seis sextantes, $60 \%$ tinham cálculo em pelo menos três sextantes e $6 \%$ apresentavam várias magnitudes de fluorose do esmalte. O CPOD foi significativamente associado com a idade e com escolaridade e as mulheres tiveram significativamente menos dentes perdidos em comparação com os homens. Os participantes tinham, em geral, altos níveis de conhecimento e atitude em relação à higiene bucal. Os resultados, no entanto, mostraram uma lacuna entre o conhecimento e a prática.

Os resultados mostram alta prevalência de cárie não tratada e má higiene bucal entre os refugiados recém-chegados na Alemanha. O estudo recomenda enfatizar a motivação nas campanhas de promoção da saúde bucal entre os refugiados e fornecer orientação adequada, preferencialmente em seu idioma nativo, sobre como acessar a atenção à saúde bucal no país anfitrião.

17. AC Høyvik; B Lie; AM Grjibovski; T Willumsen. Oral health challenges in refugees from the Middle East and Africa: A comparative study, Journal of Immigrant and Minority Health. Published online 30 June 2018.

- Refugiados com idade média de 28,5 anos.

- Origem: Síria, Irã, Iraque, Afeganistão, Eritreia, Somália Sudão e Nigéria.

- Explorar e comparar a saúde bucal e necessidade de tratamento odontológico em refugiados recém-chegados do Oriente Médio e África para a Noruega

Metade dos refugiados relataram impactos orais no desempenho diário (OIDP) e o número médio de dentes cariados foi de 4,3. Refugiados do Oriente Médio tiveram maior CPOD do que refugiados da África.

A saúde bucal é geralmente pobre em todos os atuais grupos de refugiados e tem um impacto considerável nas situações da vida cotidiana. Apesar da alta carga de cárie, a maioria das cáries era tratável. Isto, e o baixo número de dentes perdidos, indicam que a maioria dos refugiados tem os pré-requisitos para uma boa dentição, desde que recebam o tratamento dentário necessário. A inclusão de saúde bucal em programas de saúde para refugiados pode ser benéfica tanto para pacientes quanto para a comunidade.

18. SG Riatto; J Montero; DR Pérez; A Castaño-Séiquer; A Dib. Oral Health Status of Syrian Children in the Refugee Center of Melilla, Spain. Hindawi International Journal of Dentistry, 2018; Article ID 2637508, 7 p.

- Crianças de 5 a 13 anos.

- Origem: Síria.

- Determinar o estado de saúde de 6 e 12 anos, respectivamente. O ceo foi 3,2 em crianças de 6 anos. Aos 12 anos, bucal de crianças imigrantes o CPD foi de 1,6 $\pm 2,6$ dentes, o CPO-D do $1^{\circ}$ molar permanente de 1,1 dentes, e o sírias refugiadas no Centro de índice de restaurações foi de 5\%. Oitenta e seis por cento dos sextantes examinados Internamento Temporário de eram periodontalmente saudáveis. A prevalência de cárie foi alta na amostra estudada, Imigrantes em Melilla para confirmando a necessidade de um programa abrangente de atenção primária à saúde planejar programas de prevenção bucal. e assistência

19. J HunterAdams; J Cochran; LD Laird; MK PaascheOrlow; PL Geltman. Acculturation and a Potential Relationship with Oral Health Outcomes Among Somali Refugees in Massachusetts. J Immigrant Minority Health, 2018; 20:351-359

- Adultos

- Origem: Somália

- Avaliar a relação entre a aculturação e saúde oral

O estudo mostra a necessidade de avaliar melhor as repercussões da aculturação. Por exemplo, um somali que usa miswak para escovação, pode também usar escova de dentes e visitar o dentista. Barreiras linguísticas dificultam o entendimento das instruções $-60 \%$ dos refugiados alegam entender e falar em inglês. Esforços para retirar essas barreiras devem ser feitos para o melhor entendimento e ligação de culturas.

20. R Makan; M Gara; MA Awwad; Yazan Hassona. The oral health status of Syrian refugee children in Jordan: An exploratory study. Spec Care Dentist, 2019; 39:306-309

ISSN 1982-8829 Tempus, actas de saúde colet, Brasília, 13(3), 123-137, set, 2019. Epub Jul/2020 


\begin{tabular}{|c|c|}
\hline $\begin{array}{l}\text { POPULAÇÃO DE ESTUDO e } \\
\text { OBJETIVO }\end{array}$ & PRINCIPAIS RESULTADOS E CONCLUSÃO \\
\hline $\begin{array}{l}\text { - } \\
\text { - } \quad \text { Orianças de 6-12 anos } \\
\text { Avaliaria o estado de saúde } \\
\text { bucal e necessidade de } \\
\text { tratamento }\end{array}$ & $\begin{array}{l}\text { Mais da metade das } 125 \text { crianças avaliadas tinham alto risco para cárie. } 20,8 \% \text { tinham } \\
\text { dentes perdidos e } 6,4 \% \text { tinham mais de dois dentes restaurados. Quase metade tinha } \\
\text { fluorose. Dos } 52 \% \text { que receberam atendimento odontológico no campo de refugiados, } \\
\text { a maioria era para extração e prescrição medicamentosa. Apenas } 6,4 \% \text { tiveram dentes } \\
\text { restaurados e nenhuma recebeu tratamento preventivo. O estudo sugere mais informações } \\
\text { sobre tratamentos preventivos, maior número de clínicas dentro dos campos e regiões } \\
\text { próximas e educação em saúde bucal para refugiados. }\end{array}$ \\
\hline \multicolumn{2}{|c|}{$\begin{array}{l}\text { 21. AM Moreau; F Hennous; B Dabbagh; BF Santos. Oral Health Status of Refugee Children in Montreal. Journal of Immigrant } \\
\text { and Minority Health, 2019; 21:693-698 }\end{array}$} \\
\hline $\begin{array}{l}\text { - Crianças de } 1-14 \text { anos } \\
\text { Levantar dados sobre saúde } \\
\text { bucal de crianças refugiadas } \\
\text { e avaliar questões } \\
\text { sociodemográficas que }\end{array}$ & $\begin{array}{l}120 \text { crianças refugiadas e } 117 \text { no grupo controle (crianças canadenses). Cerca de } 60 \% \\
\text { das refugiadas nunca haviam visitado o dentista, enquanto as canadenses já haviam tido } \\
\text { a experiência no último ano. Crianças refugiadas tinham índice CPOd maior que as } \\
\text { canadenses. Melhorar o acesso deve ser uma prioridade, uma vez que crianças refugiadas } \\
\text { têm pior saúde bucal que canadenses. }\end{array}$ \\
\hline
\end{tabular}

\section{DISCUSSÃO}

Os principais problemas bucais, cárie dentária e doença periodontal, são comuns nos refugiados e também na população em geral. Um dos desafios reside na oferta de cuidados bucais no país de reassentamento. O Brasil possui um sistema de saúde universal e gratuito, e as demandas de saúde e de saúde bucal podem ser direcionadas ao sistema.

Uma das conjunturas encontradas neste estudo foi a do "imigrante saudável". Na chegada ao país de reassentamento sua situação de saúde, bucal e geral, muitas vezes é melhor do que a dos nativos do país. No entanto, a partir de um certo tempo de permanência, passa a ter um quadro de saúde preocupante, evoluindo para uma situação semelhante aos habitantes nativos. Este processo é de aculturação, no qual atitudes e comportamentos do país de reassentamento passam a ser incorporados pela população migrante.

O processo de aculturação pode ser percebido de diversas formas. Uma delas é a experiência de cárie dentária em algumas populações de refugiados. Mesmo que a população tenha tido pouco ou nenhum acesso a serviços odontológicos em seus países, muitos não apresentam história prévia da doença. Mas no contato com uma nova cultura e hábitos dietéticos com forte incorporação de carboidratos fermentáveis, os problemas bucais começam a surgir; e os indicadores de doenças passam a ser semelhantes aos dos nativos..$^{18,35,36,37,38,39,40}$

Sabe-se que a população que professa o islamismo tem um ritual de orações em que a higiene pessoal tem um papel importante. Outras populações utilizam meios mecânicos naturais para a higiene bucal, de acordo com as tradições de seu país de origem, e a conjunção dos métodos e técnicas pode ser a melhor forma de adoção de cuidados bucais, sem que seja necessária a aculturação das pessoas migrantes. O respeito às diversas culturas e a possibilidade de adoção de novos hábitos podem ser a chave para uma atenção integral à saúde. ${ }^{41}$

Os desafios para países que os recebem são de várias situações, em especial no que se refere à 
saúde destas pessoas. Um fenômeno recente de migração no Brasil ocorre pela vinda de diversos países, como Haiti, Palestina, Senegal, Síria e, mais recentemente, venezuelanos.

Este estudo buscou analisar as circunstâncias que cercam a saúde bucal das populações migrantes, como forma de buscar subsídios para a adoção de ações e serviços de saúde voltados para as pessoas que chegam ao país para viver e trabalhar.

Mesmo que a maioria dos refugiados passe por um check-up médico ao chegar ao país de assentamento, alocado pela ACNUR, este não inclui cuidados dentários. ${ }^{14} \mathrm{Com}$ esta situação, observa-se claramente a necessidade de incluir estes cuidados, considerando a integralidade da atenção em saúde, um dos princípios doutrinários do SUS.

Uma das primeiras barreiras encontradas pelos migrantes é a da língua. Embora as Diretrizes Curriculares Nacionais brasileiras $(\mathrm{DCN})^{38}$ dos cursos da área da saúde orientem para o domínio de pelo menos uma língua estrangeira e de tecnologias da informação, não é sabido se estas habilidades e competências são efetivamente ativadas nos cursos de graduação. Considerando a possibilidade de acesso das UBS à internet, os profissionais ligados ao SUS poderiam lançar mão de ferramentas disponíveis gratuitamente na rede para facilitar o processo de comunicação. ${ }^{39}$

O desconhecimento acerca do sistema de saúde do país de acolhimento pode ser motivo de preocupação para o refugiado, pois tendo passado por experiências traumáticas que muitas vezes incluem violência física e psicológica, a figura de autoridades, inclusive da área da saúde, é vista com desconfiança ou temor. ${ }^{41}$

No Brasil e na América Latina, pesquisas devem ser feitas sobre saúde bucal de refugiados e imigrantes, principalmente os em situação de vulnerabilidade, a fim de se obter mais conhecimento sobre o tema. A realidade atual sobre migrações no Brasil deve ser avaliada de forma única, uma vez que nem sempre as condições de refúgio dos países trazidos neste trabalho se aplicam ao País.

\section{CONSIDERAÇÕES FINAIS}

Percebe-se que grande parte dos problemas relativos a acesso, acolhimento e saúde bucal de refugiados, conforme encontrado na literatura, podem ser contemplados pelas diretrizes e políticas de saúde do SUS e pelas DCN dos cursos de saúde.

O presente estudo mostra a necessidade de ampliação de políticas públicas, adequandoas à situação atual de migração, na qual se pode utilizar conhecimentos técnicos, científicos e tecnológicos para auxiliar nessa transição. Uma das estratégias de grande impacto para que as equipes de saúde sejam preparadas para essas novas situações é através da educação permanente em saúde.

Os profissionais de saúde devem ser preparados para lidar com a cultura e as experiências

ISSN 1982-8829 Tempus, actas de saúde colet, Brasília, 13(3), 123-137, set, 2019. Epub Jul/2020 
anteriores dessa população com relação aos cuidados bucais. Deve-se conhecer hábitos, crenças e atitudes de cada país de origem dos reassentados.

Também é mostrada a importância de vínculo com essa população desde o momento de sua chegada ao país, uma vez que a literatura mostra que a partir do processo de aculturação, sua saúde pode debilitar ao longo do tempo.

\section{REFERÊNCIAS BIBLIOGRÁFICAS}

1. BUSKO, Danielle R. Políticas Públicas Educacionais para Imigrantes e Refugiados: Rede de Acolhimento no Rio Grande do Sul. Defensoria Públ. União. Brasília, DF, n.10, p. 1-504. jan/ dez. 2017.

2. MARINUCCI, Roberto. O fenômeno migratório no Brasil. In: Instituto Migrações e Direitos Humanos. Brasília. 2002. Disponível em: <http://www.migrante.org.br/index.php/ migrantes2/195-o-fenomeno-migratorio-no-brasil>. Acesso em: 16 out. 2018.

3. BIGOT, Antoine et al. Médecins Sans Frontières. Refugee Health - An approach to emergency situations. $383 \mathrm{p}$.

4. SAYAD, Abdelmalek. O que é um imigrante? A imigração ou os paradoxos da alteridade. Peuples méditerranéens. França, n. 7, p. 3-23, abr/jun. 1979

5. ACNUR. Convenção relativa ao estatuto dos refugiados (1951). Disponível em: $<$ http:// www.acnur.org/fileadmin/Documentos/portugues/BDL/Convencao_relativa_ao_Estatuto_dos_ Refugiados.pdf $>$. Acesso em: 17 maio 2018.

6. GOMBATA, Marsílea. Há dez anos no Haiti, Brasil vive impasse. In: Carta Capital. Disponível em: <https:/www.cartacapital.com.br/revista/811/ha-dez-anos-no-haiti-brasil-viveimpasse-8874.html>. Acesso em: 16 out. 2018.

7. BRASIL. Ministério da Defesa. O Brasil na MINUSTAH (Haiti). Disponível em: $<$ https://www.defesa.gov.br/relacoes-internacionais/missoes-de-paz/o-brasil-na-minustah-haiti $>$. Acesso em: 30 nov. 2018.

8. BRASIL. Ministério da Justiça. Secretaria Nacional de Justiça. Refúgio em Números $-3^{\text {a }}$ edição. Brasil. 30 p. Abr. 2018.

9. BRASIL. Lei $n^{\circ}$ 13.445, de 24 de maio de 2017. Institui a Lei de Migração. Diário Oficial da União. Seção 1, 25 maio 2017, p. 1. Disponível em: <http://www2.camara.leg.br/legin/fed/ lei/2017/lei-13445-24-maio-2017-784925-publicacaooriginal-152812-pl.html>. Acesso em: 15 maio 2018. 
10. ACNUR. Coletânea de Instrumentos de Proteção Nacional e Internacional de Refugiados e Apátridas. ACNUR/ONU. 266 p. Brasília, 2016. Disponível em: < http://www. acnur.org/portugues/wp-content/uploads/2018/02/Colet\%C3\%A2nea-de-Instrumentos-deProte\%C3\%A7\%C3\%A3o-Nacional-e-Internacional.pdf>. Acesso em: 26 ago. 2018.

11. BRASIL. Lei $\mathrm{n}^{0} 8.080$, de 19 de setembro de 1990. Dispõe sobre as condições para a promoção, proteção e recuperação da saúde, a organização e o funcionamento dos serviços correspondentes e dá outras providências. Brasília, 19 de setembro de 1990; $169^{\circ}$ da Independência e $102^{\circ}$ da República. Disponível em: < http://www.planalto.gov.br/ccivil_03/Leis/ L8080.htm>. Acesso em: 3 ago. 2018.

12. BRASIL. Ministério da Saúde. Portaria nº 2.436, de 21 de setembro de 2017. Aprova a Política Nacional de Atenção Básica, estabelecendo a revisão de diretrizes para a organização da Atenção Básica, no âmbito do Sistema Único de Saúde (SUS). Diário Oficial da União. Disponível em:<http://bvsms.saude.gov.br/bvs/saudelegis/gm/2017/prt2436_22_09_2017. html>. Acesso em: 18 set. 2018

13. FALAGAS, Matthew E et al. Comparison of PubMed, Scopus, Web of Science, and Google Scholar: strengths and weaknesses. The FASEB Journal, 2008; v. 22, n. 2, p. 338-342.

14. ROUCKA, T M. Access to dental care in two long-term refugee camps in western Tanzania; programme development and assessment. International Dental Journal, n.61, p.109115. 2011.

15. SARRI, G. et al. A school-based epidemiological study of dental neglect among adolescents in a deprived area of the UK. British Dental Journal. Reino Unido; n. e17, pp. 213. 2012.

16. RIGGS, E. et al. Breaking down the barriers: a qualitative study to understand child oral health in refugee and migrant communities in Australia. Ethnicity \& Health. Austrália; v. 20, n. 3, p. 241-257. 2015.

17. NICOL, P. et al. Caries burden and efficacy of a referral pathway in a cohort of preschool refugee children. Australian Dental Journal. Austrália; n. 60, p. 73-79. 2015.

18. DAVIDSON, N. et al. Comprehensive health assessment for newly arrived refugee children in Australia. J. Paediatr. Child Health. Austrália; n. 40, p. 562-568. 2004.

19. GELTMAN, P. L. et al. The Impact of Functional Health Literacy and Acculturation on the Oral Health Status of Somali Refugees Living in Massachusetts. Am J Public Health. EUA; n.8, v. 103, p. 1516-1523. 2013. 
20. QUACH, A. et al. Gaps in smiles and services: a cross-sectional study of dental caries in refugee-background children. BMC Oral Health. Austrália; n. 15, pp. 10. 2015.

21. JOHNSTON, V. et al. The health of newly arrived refugees to the Top End of Australia: results of a clinical audit at the Darwin Refugee Health Service. Australian Journal of Primary Health. Austrália; n. 18, p. 242-247. 2012.

22. NICOL, P. et al. Informing a culturally appropriate approach to oral health and dental care for pre-school refugee children: a community participatory study. BMC Oral Health. Austrália, n. 14, pp. 11. 2014.

23. SHAH, A. Y. et al. Nutritional status of refugee children entering DeKalb County, Georgia. J Immigrant Minority Health. EUA; n. 16, p. 959-967. 2014.

24. REZA, M. et al. Oral health status of immigrant and refugee children in North America: A scoping review. J Can Dent Assoc. Canadá; n. 82, v. g3, pp. 18. 2016.

25. HOOVER, J. et al. [Online] Risk determinants of dental caries and oral hygiene status in 3-15-year-old recent immigrant and refugee children in Saskatchewan, Canada: A pilot study. J Immigrant Minority Health. Canadá. 2016. Disponível em: <http://www.springerlink.com>. Acesso em: 18 ago. 2017.

26. MUTCH, R. C. et al. Tertiary paediatric refugee health clinic in Western Australia: Analysis of the first 1026 children. Journal of Paediatrics and Child Health. Austrália, n. 48, p. 582-587. 2012.

27. GHIABI, E. et al. The oral health status of recent immigrants and refugees in Nova Scotia, Canada. J Immigrant Minority Health. Canadá, n. 16, p. 95-101. 2014.

28. GOETZ, K. [Online] Assessment of oral health and cost of care for a group of refugees in Germany: a cross-sectional study. BMC Oral Health. Austrália, n. 18, p. 69. 2018.

29. SOLYMAN, M. S-WESTHAUSEN, A-M. Oral health status among newly arrived refugees in Germany: a cross-sectional study. BMC Oral Health. Austrália, n. 18, p. 132. 2018.

30. HOYVIK, A. C. et al. [Online] Oral health challenges in refugees from the Middle East and Africa: A comparative study. Journal of Immigrant and Minority Health. Canadá. 2018.

31. RIATTO, S. G. et al. Oral Health Status of Syrian Children in the Refugee Center of Melilla, Spain. Hindawi International Journal of Dentistry. BRASIL; pp. 7. 2018.

32. HUNTER-ADAMS, J. et al. [Online] Acculturation and a Potential Relationship with Oral Health Outcomes Among Somali Refugees in Massachusetts. J Immigrant Minority Health. 
Canadá, n. 20, p 351-359. 2018.

33. MAKAN, R. et al. The oral health status of Syrian refugee children in Jordan: An exploratory study. Spec Care Dentist. EUA, n. 39, p. 306-309. 2019.

34. MOREAU, AM. et al. Oral Health Status of Refugee Children in Montreal. Journal of Immigrant and Minority Health. Austrália, n. 29, p. 693-698. 2019.

35. HOYVIK, A. C. et al. [Online] Oral health challenges in refugees from the Middle East and Africa: A comparative study. Journal of Immigrant and Minority Health. Canadá. 2018.

36. RIATTO, S. G. et al. Oral Health Status of Syrian Children in the Refugee Center of Melilla, Spain. Hindawi International Journal of Dentistry. BRASIL; pp. 7. 2018.

37. ADAMS, J.H et al. The Cultural Basis for Oral Health Practices among Somali Refugees Pre- and Post-Resettlement in Massachusetts. J Health Care Poor Underserved. EUA; n. 4, v. 24, p. 1474-1485. 2013.

38. COTE, S. et al. Dental Caries of Refugee Children Compared With US Children. Pediatrics, v. 114, n. 6. 2004.

39. ENWONWU, C. O. et al. Nutrition and oral health in Africa. International Dental Journal. EUA, n. 54, p. 344-351. 2004.

40. RIGGS, E. et al. Refugee child oral health. Oral Diseases. Austrália; n. 23, p. 292-299. 2017.

41. STACEY, Aisha. Higiene Pessoal (parte 1 de 2): limpeza é metade da fé. In: The Religion of Islam. 2015. Disponível em: <https://www.islamreligion.com/pt/articles/2149/ viewall/higiene-pessoal-parte-1-de-2/>. Acesso em 26 out. 2018.

Artigo apresentado em setembro de 2019 Artigo aprovado em janeiro de 2020 Artigo publicado em julho de 2020 